\title{
Pemberdayaan Angkutan Umum Sebagai Angkutan Sekolah Di Kecamatan Pare, Kabupaten Kediri
}

\author{
Djamal Sebastian, Putri Intan Cahyaningrum, Aan Sunandar \\ Politeknik Transportasi Darat Indonesia - STTD \\ Email:djamal.sebastian@ptdisttd.ac.id
}

\begin{abstract}
ABSTRAK
Pelajar Sekolah Menengah Pertama dan Atas di Kecamatan Pare lebih memilih kendaraan pribadi dibanding angkutan umum untuk menuju ke sekolah. Hal ini dikarenakan angkutan umum yang sulit didapatkan, pelayanan yang dianggap tidak sesuai dengan keinginan dan belum dapat mengakses daerah asal- tujuan. Untuk itu diperlukan penyediaan sarana bagi pelajar di Kecamatan Pare berupa angkutan sekolah serta untuk mempertahankan keberadaan angkutan pedesaan. Metode pengumpulan data dilakukan dengan cara mengumpulkan informasi melalui kuisioner online yang diberikan kepada pelajar Sekolah Menengah Pertama dan Atas yang akan dilayani angkutan sekolah sebagai data primer. Data sekunder berupa jumlah seluruh siswa, lokasi masing-masing sekolah, dan trayek angkutan pedesaan. Analisis menggunakan matriks asal- tujuan yang menjadi dasar untuk mengetahui demand angkutan sekolah. Kemudian dilakukan analisis penentuan rute, analisis operasional yang dihitung secara aktual dan potensial yang menjadi acuan untuk merencanakan penjadwalan, biaya operasional dan tarif. Hasil penelitian menunjukkan bahwa jumlah permintaan angkutan sekolah adalah 457 siswa untuk permintaan aktual dan 6785 siswa untuk permintaan potensial dan terbanyak yaitu zona 2 dengan jumlah kebutuhan armada total pada permintan aktual sebanyak 2 kendaraan dan permintaan potensial sebanyak 8 kendaraan. Terdapat dua rute rencana dengan panjang rute $5.3 \mathrm{~km}$ dan $7.1 \mathrm{~km}$, dengan jadwal pengoperasiannya dibagi menjadi shift pagi satu jam dan shift siang dua jam. Tarif yang akan dikelurkan untuk angkutan sekolah sebesar Rp3.000,00 /pnp-trip. Untuk meningkatkan pelayanan angkutan sekolah, maka harus mulai beroperasi maksimal pukul 06.15 WIB dan pukul 13.00 WIB. Selain itu fasilitas di dalam armada angkutan sekolah harus terpenuhi.
\end{abstract}

Kata kunci : Angkutan sekolah, rute, operasional, tarif

\section{ABSTRACT}

Junior high school and senior high school student in Pare District prefer private vehicle over public transport when going to school. The reason are the public transport was rarely available, service that not accordingly to passenger, and cannot reach origin and destination area. For it is necessary to provide vehicle for student in Pare District which is school transports along with the existence of rural transports. The collecting data method was 
done by collecting information through online quisioner that given to students of junior high school and senior high school which will be served by school transports as primary data. Secondary data consist of the total of students, every school location, rural transports track. Analysis was done by using origin and destination matrix which become basis to know the demand of school transports. After that, the analysis that was done are analysis to determine route, operational analysis that was calculated actual and potential then become reference to plan schedule, operational cost and tariff. The result of research show that demand of school transport is 457 student for actual demand and 6785 student for potential demand and the biggest amount of demand is zone 2 with the total of actual vehicle need is 2 and potential demand is 8 vehicle. There are two scheme route with a total of 5.3 $\mathrm{km}$ and $7.1 \mathrm{~km}$, the operation schedule is divided into route 1 operated for one rit of one hour morning shift and route 2 operated for 4 rit of two afternoon shift. Tariff for school transport is Rp3.000,00 /passenger-trip. In order to increase the service of school transport, it has to be operated maximally 06.15 WIB and 13.00 WIB. Furthermore, the facility inside the school transport vehicle has to be fulfilled.

Keyword: School transport, route, tariff

\section{A. PENDAHULUAN}

Kabupaten Kediri memiliki potensi beberapa jenis kegiatan diantaranya pertanian, perkebunan, industri, pemerintahan, pendidikan, logistik, dan perdagangan. Dalam hal pendidikan, sekolah memiliki peran yang besar terhadap kemajuan generasi muda. Kabupaten Kediri lebih memusatkan kegiatan pendidikan pada satu kecamatan yaitu Kecamatan Pare. Kecamatan Pare memiliki jumlah pelajar yang cukup banyak yang tersebar di beberapa sekolah. Terdapat 12 SMP (Sekolah menengah Pertama) dengan peserta didik sejumlah 4.857 siswa, 16 SMA/sederajad dengan peserta didik sejumlah 8.526 siswa (sumber: Data Pokok Pendidikan Menengah di Kecamatan Pare, Kementrian Pendidikan dan Kebudayaan, 2020).

Angkutan umum yang melintas di Kecamatan Pare terdiri dari AKDP (Angkutan Kota Dalam Provinsi) dan Angkutan Pedesaan (Angdes). Pada kondisi eksisting angkutan pedesaan yang ada di Kabupaten Kediri berpusat di Kecamatan pare. Berdasarkan hasil survey angkutan umum PKL Kabupaten Kediri tahun 2019, trayek angkutan pedesaan yang beroperasi di Kecamatan Pare terdapat 4 jaringan trayek.

Dilakukan survey angkutan umum oleh Tim PKL Kabupaten Kediri tahun 2019 yang dilakukan kepada 109 penumpang dari 4 (empat) jaringan trayek angkutan pedesaan didapatkan maksud perjalanan menggunakan angkutan umum diantaranya untuk bekerja (30\%), belanja (30\%), sekolah (29\%), dan sosial (11\%). Sebanyak 29\% pengguna angkutan pedesaan adalah penumpang usia 14-19 tahun yang merupakan pelajar.

Dari hasil survey Taruna/i PTDI-STTD yang dilakukan secara acak terhadap 269 pelajar sebagai sampel menunjukkan pelajar di Kecamatan Pare lebih banyak yang menggunakan kendaraan pribadi (sepeda motor) dan antar- jemput menuju dan kembali dari sekolah sebanyak $93.7 \%$. Karena terbatasnya trayek angkutan umum yang tersedia dan 
beberapa ruas jalan yang melarang angkutan umum untuk melintas sehingga siswa lebih memillih untuk menggunakan kendaraan pribadi atau antar-jemput yang dianggap lebih fleksibel.

Pengamatan langsung yang dilakukan Tim PKL Kabupaten Kediri 2019 didapatkan bahwa adanya aktivitas antar-jemput oleh orang tua yang menyebabkan timbulnya kepadatan lalulintas di dekat pintu masuk sekolah karena kendaraan pengantar berhenti di badan jalan. Hal ini menunjukkan kurangnya minat pelajar untuk menggunakan angkutan umum.

Berdasarkan hasil survey yang dilakukan Tim PKL Kabupaten Kediri 2019 mengenai pendapat responden terhadap angkutan umum saat ini menunjukkan yang tertinggi untuk saat ini adalah sulit didapatnya angkutan umum dengan persentase $49 \%$.

Dari hasil pengamatan langsung yang dilakukan terhadap angkutan pedesaan didapat bahwa jam operasional angkutan pedesaan mengikuti waktu berangkat sekolah pelajar dan awal kegiatan pasar di Pare dan berakhir ketika jam pulang sekolah siswa, yaitu dimulai pukul 06.00 WIB - 14.00 WIB. Pendeknya jam operasional angkutan pedesaan disebabkan oleh berkurangnya minat masyarakat karena pelayanan yang dianggap tidak sesuai dengan keinginan serta belum dapat mengakses daerah asal-tujuan.

Berdasarkan data Satlantas Polres dan Polresta Kediri, tingkat kecelakaan lalu lintas di Kabupaten Kediri berdasarkan usia pada tahun 2018, usia antara 13-25 tahun memiliki nilai kecelakaan tertinggi kedua, yaitu sebanyak 620 kejadian (30\%) yang disebabkan penggunaan kendaraan. Dikarenakan pada usia tersebut termasuk usia produktif, hal ini mengkhawatirkan bagi para pelajar yang banyak menggunakan kendaraan bermotor. Penggunaan sepeda motor oleh pelajar dikhawatirkan menimbulkan tingkat kecelakaan yang tinggi di kalangan usia sekolah dan perilaku pelajar dalam penggunaan sepeda motor yang kurang berkeselamatan.

Seluruh kegiatan di Kabupaten maupun Kota memerlukan transportasi, transportasi adalah kebutuhan mutlak untuk angkutan orang maupun barang. Transportasi merupakan suatu kegiatan yang sangat berperan sebagai penggerak pembangunan dan perekonomian suatu daerah. Upaya pengembangan pembangunan dan perekonomian dalam transportasi harus didukung dengan adanya jalur pergerakan secara nasional atau internasional, baik melalui transportasi darat, laut maupun udara agar terciptanya suatu tujuan pembangunan dan perekonomian dapat berjalan dengan selamat tertib, aman, lancar dan nyaman.

Dalam rangka penyediaan sarana bagi pelajar di Kecamatan Pare dan untuk mempertahankan keberadaan angkutan pedesaan, Dinas perhubungan Kabupaten Kediri berencana untuk pengadaan angkutan sekolah dengan menggunakan angkutan umum yang tersedia saat ini.

Berdasarkan uraian di atas, maka perlu dilakukan suatu penelitian mengenai pemberdayaan angkutan umum sebagai angkutan sekolah di Kecamatan Pare, Kabupaten Kediri. Penelitian ini diharapkan mampu memberikan pemecahan terhadap masalah penyediaan angkutan umum bagi pelajar yang aman dan selamat.

\section{B. KAJIAN LITERATUR}

\section{Definisi Angkutan Sekolah}

a) Angkutan Sekolah adalah angkutan yang khusus melayani angkutan murid-murid sekolah. (Sumber : Kamus Besar Bahasa Indonesia); 
b) Angkutan Kota/Pedesaan anak sekolah adalah angkutan dalam trayek tetap dan teratur yang khusus melayani siswa sekolah. (SK. Dirjen No. 967 Tahun 2007).

\section{Siswa}

Siswa atau pelajar yaitu anak sekolah (terutama pada sekolah dasar dan sekolah lanjutan). (Sumber : Kamus Besar Bahasa Indonesia).

\section{Armada}

Aset berupa kendaraan mobil angkutan/MPU yang merupakan tanggung jawab perusahaan, baik yang dalam keadaan siap guna dalam konservasi. (SK. Dirjen No. 687 Tahun 2002).

\section{Kapasitas Angkut/Kapasitas Tersedia}

Kapasitas Angkut/Kapasitas Tersedia adalah kapasitas maksimal yang tersedia untuk penumpang (duduk dan berdiri) sesuai dengan ketentuan yang berlaku. (SK. Dirjen No. 687 Tahun 2002).

\section{Faktor Muat Kendaraan (Load Factor)}

Faktor muat (load factor) adalah rasio perbandingan antara jumlah penumpang yang di angkut dengan kapasitas kendaraannya yang biasanya dinyatakan dalam persen (\%). Faktor muat rata-rata dalam perencanaan suatu jaringan trayek adalah $70 \%$ diambil pada saat kondisi dinamis. (SK. Dirjen No. 687 Tahun 2002).

\section{Kriteria Angkutan Umum Untuk Angkutan Sekolah}

Masalah-masalah yang dihadapi layanan transportasi sekolah penekanannya pada 4 (empat) kriteria, yaitu :

a) Keselamatan

Keselamatan ini sebagian merupakan masalah pendidikan dan sebagiannya merupakan masalah kondisi angkutan-angkutan sekolah yang mengangkut para siswa.

b) Ekonomi

Dapat dilakukan penghematan jika rute-rute angkutan dirubah, mengatur daftar rencana perjalanan atau menganalisa secara ekonomis.

c) Kecukupan

Pelayanan angkutan sekolah adalah cukup bila dihubungkan dengan perbandingan murid-murid sekolah yang tinggal melebihi jarak satu mil dari sekolah dimana transportasi disediakan. Ketentuan ini berbeda-beda secara luas dalam suatu aturan wajib belajar.

d) Efisiensi

Efisiensi merupakan salah satu kriteria yang lain yang semestinya diterapkan dalam mengevaluasi transportasi siswa (Kusmintarjo, 1993).

\section{Penggunaan Angkutan Umum sebagai Angkutan Sekolah}

Perencanaan angkutan umum yang digunakan sebagai angkutan sekolah ini menjadi jalan keluar untuk tetap mempertahankan angkutan umum yang ada dan menjadi pilihan bagi 
siswa untuk berangkat dan pulang sekolah dengan aman, nyaman, dan selamat. Program ini menjadi spesial karena angkutan kota yang ada di Tabanan memiliki 2 trayek, yaitu :

a) Trayek utama yang merupakan trayek dasar pelayanan penumpang umum dari terminal atau lokasi asal ke terminal atau lokasi tujuan.

b) Trayek angkutan Siswa Trans Serasi yang merupakan deviasi atau penyimpanngan trayek utama yang melayani siswa dari zona asal perjalanan siswa melalui kantongkantong penumpanng siswa ke dan dari sekolah pada jam berangkat dan pulang sekolah baik sekolah pagi maupun sekolah siang.

\section{Karakteristik Perjalanan Siswa}

Perjalanan siswa yang dimaksud adalah perjalanan dengan tujuan sekolah. Pada umumnya perjalanan siswa bersifat home based dan merupakan perjalanan simple chain. Perjalanan dengan tujuan sekolah biasanya dimulai dan di akhiri pada waktu yang bersamaan atau dengan kata lain, tarikan dan bangkitan suatu land use sekolah terjadi pada waktu yang telah ditentukan.

\section{Rute}

Rute adalah jalur yang diambil bus dan angkutan umum sejak meninggalkan titik awalnya hingga sampai tujuan Terdapat beberapa asumsi mengenai rute diantaranya (Belcher. J, Britt. D, et al, 2005) :

a) Semua jalan yang digunakan dipelihara oleh pemerintah kabupaten.

b) Sedikit penyimpangan yang terjadi.

c) Pelajar yang belum mendapat pelayanan angkutan sekolah diperbolehkan menggunakan transportasi sendiri.

d) Daerah yang mendapat pelayanan angkutan sekolah yaitu yang dilewati rute pilihan.

e) Adanya perbedaan jarak antar sekolah maka harus sedikit deviasi dalam jadwal sekolah antar sekolah.

\section{METODE}

Penelitian di awali dengan mengidentifikasi masalah yang ada. Data diperoleh dari hasil survei sebagai data primer dan data yang berasal dari hasil laporan milik pemerintah setempat sebagai data sekunder. Penelitian dilaksanakan di Kawasan pendidikan di Kabupaten Kediri, tepatnya di Kecamatan Pare. Penelitian dilaksanakan dengan bantuan dari program Visum.

\section{HASIL DAN PEMBAHASAN}

\section{Analisis Permintaan Penumpang Angkutan Sekolah}

Perhitungan permintaan penumpang angkutan sekolah didapatkan dari penumpang aktual dan penumpang potensial. Permintaan aktual merupakan siswa yang saat ini ke sekolah menggunakan angkutan umum. Permintaan aktual diperoleh dari matrik pengguna angkutan umum yang didapatkan dari matrik asal tujuan siswa per hari dikalikan dengan persentase siswa yang menggunakan angkutan umum. Matrik asal tujuan siswa menggunakan angkutan umum menunjukkan bahwa permintaan penumpang aktual adalah 
sebanyak 457 siswa.

Sedangkan permintaan potensial didapatkan dari siswa pengguna angkutan umum dengan maksud bersekolah ditambah dengan pengguna angkutan pribadi yang bersedia berpindah ke angkutan sekolah. Ada pun matrik pengguna angkutan pribadi yang bersedia berpindah moda didapatkan dari persentase kesediaan siswa berpindah moda per sekolah dikalikan dengan matrik pengguna kendaraan pribadi tiap sekolah. Permintaan penumpang potensial secara keseluruhan adalah sebanyak 6785 orang. Untuk permintaan potensial tertinggi adalah perjalanan siswa yang berasal dari zona 2 yaitu sebanyak 920 orang.

\section{Analisis Penentuan Rute Angkutan Sekolah}

Pendekatan yang digunakan dalam perencanaan rute angkutan sekolah adalah pendekatan secara manual, yang mana pendekatan ini mempertimbangkan zona asal dan zona tujuan yang memiliki permintaan terbanyak, dan disesuaikan dengan klasifikasi jalan, pertimbangan jarak jalan serta fungsi jalan.

Penentuan rute dapat dilakukan dengan bantuan pembebanan software Visum. Dengan jumlah permintaan yang dimasukkan adalah jumlah perjalanan pelajar sekolah di Kecamatan Pare yang menggunakan angkutan umum yang telah ada dan dengan adanya minat dan kesediaan berpindah moda dari pengguna kendaraan pribadi. Sehingga didapat rute angkutan sekolah dengan demand paling optimal yang akan digunakan sebagai rute. Selain itu sebelum menentukan rute yang akan dilewati maka perlu diperhitungkan kondisi prasarana jalur dengan melihat hasil dari inventarisasi jalan. Data-data yang telah dikumpulkan selanjutnya digunakan untuk menganalisis kinerja lalu lintas maupun sistemnya yang dibantu dengan paket aplikasi Visum.

Berdasarkan hasil plotting demand untuk tiap-tiap ruas pada peta jaringan jalan, selanjutnya demand pada ruas tersebut akan direncanakan sebagai rute angkutan sekolah dengan mempertimbangkan ketentuan tersebut yaitu ditentukan ruas jalan mana saja dengan jumlah demand penumpang yang tinggi.

Diambil dua rencana rute dalam perencanan pengoperasian angkutan sekolah. Masing-masing rute memiliki cakupan wilayah tersendiri dan mewakili permintaan perjalanan berdasarkan hasil pembebanan perjalanan siswa sekolah pada kondisi awal. Keseluruhan dari perencan aan rute tersebut telah disesuaikan dengan pertimbanganpertimbangan seperti yang telah dijelaskan sebelumnya.

\section{Analisis Operasional Angkutan Sekolah}

a) Angkutan Sekolah

Butuh operasional yang tepat agar angkutan sekolah yang direncanakan berjalan dengan baik, artinya setiap operasinya akan berjalan sesuai harapan dan mendapatkan hasil sehingga dapat dinilai efisien dan efektif. Pertama-tama yang perlu ditentukan adalah jumlah armada yang tepat agar permintaan dari masing-masing zona dapat terlayani, dengan menentukan waktu operasi, headway kendaraan, dan kecepatan rencana kendaraan.

b) Angkutan Umum

1) Faktor Muat Kendaraan

Faktor muat atau load factor adalah perbandingan antara jumlah penumpang yang diangkut dengan kapasitas kendaraan yang tersedia. Penentuan kapasitas 
untuk kendaraan yang akan dioperasikan adalah disesuaikan dengan daya angkut angkutan umum yang diizinkan. Faktor muat yang digunakan dalam perencanaan angkutan sekolah di Kecamatan Pare ini adalah 100\% dari kapasitas kendaraan. Faktor muat angkutan pedesaan terbesar pada shift 1 adalah $69 \%$ dan pada shift 2 yaitu $142 \%$.

2) Waktu Tempuh Angkutan Perdesaan

Waktu perjalanan angkutan umum merupakan waktu yang ditempuh oleh kendaraan angkutan umum ketika melakukan perjalanan dari awal sampai akhir dari trayek tersebut. waktu tempuh terbesar ada pada trayek Pare - Besowo, hal ini dikarenakan semakin panjang rute trayek maka semakin lama waktu tempuh yang dibutuhkan.

3) Waktu Sirkulasi Angkutan Perdesaan

Round Trip Time (RTT) adalah waktu perjalanan pulang-pergi pada suatu trayek angkutan umum yang dihitung bersama hambatan- hambatannya. Waktu sirkulasi terbesar adalah trayek Pare - Besowoyang membutuhkan waktu selama 78.07 menit untuk perjalanan bolak-ballik dari titik A-B-A

4) Waktu Antar Kendaraan

Jarak antar kendaraan angkutan umum merupakan waktu antara kendaraan pertama dengan waktu kendaraan kedua. Headway terbesar terjadi pada trayek Pare - Papar yaitu shift pagi selama 32 menit dan shift siang selama 92 menit.

5) Frekuensi

Frekuensi angkutan umum merupakan jumlah kendaraan yang melewati satu titik dalam satu trayek pada tiap jamnya. Frekuensi terbesar adalah trayek Pare Besowo sebanyak 8 frekuensi pada shift pagi dan 3 frekuensi pada shift siang, sehingga pelayanan angkutan pedesaan dapat terpenuhi.

\section{Analisis Jumlah Kebutuhan Armada}

Perhitungan mengenai jumlah kebutuhan armada yang akan beroperasi ditentukan dengan melihat jumlah permintaan terhadap pelayanan jasa angkutan sekolah selain menggunakan data permintaan penumpang, data perhitungan manajemen operasi angkutan seperti waktu sirkulasi dan waktu antara (headway) kendaraan juga digunakan dalam menentukan jumlah armada yang akan beroperasi.

Berdasarkan data sekunder yang didapat saat melakukan Praktek Kerja Lapangan di Kabupaten Kediri tahun 2019, armada angkutan umum yang ada saat ini adalah sebanyak 11 unit. Jika digunakan untuk keperluan angkutan sekolah pada pagi dan siang hari maka armada yang dibutuhkan sebanyak 8 unit dari 11 unit yang sudah ada. Jadi, pada saat angkutan sekolah sedang beroperasi, sebanyak 3 unit masih bisa beroperasi seperti biasa untuk melayani penumpang angkutan umum dengan tujuan selain bersekolah.

\section{Analisis Penjadwalan Angkutan Sekolah}

Penjadwalan angkutan sekolah merupakan hasil akhir dari analisis manajemen operasi angkutan yang telah dilakukan. Tujuan utama dari penjadwalan ini adalah membuat semua rencana perjalanan agar dapat dilaksanakan dengan baik.

Penjadwalan angkutan sekolah berdasarkan permintaan aktual untuk MPU 1 shift pagi sebanyak 1 perjalanan terjadwal dengan waktu berangkat di titik awal pada pukul 06.15 
WIB dan tiba di titik akhir pada pukul 06.26 WIB.

Penjadwalan angkutan sekolah berdasarkan permintaan aktual untuk MPU 2 shift pagi sebanyak 1 perjalanan terjadwal dengan waktu berangkat di titik awal pada pukul 06.15 WIB dan tiba di titik akhir pada pukul 06.29 WIB.

Penjadwalan angkutan sekolah berdasarkan permintaan potensial untuk MPU 1 shift pagi sebanyak 4 perjalanan terjadwal dengan waktu berangkat perjalan pertama di titik awal pada pukul 06.15 WIB dan waktu tiba perjalnan terakhir di titik akhir pada pukul 07.22 WIB.

Penjadwalan angkutan sekolah berdasarkan permintaan potensial untuk MPU 1 shift pagi sebanyak 4 perjalanan terjadwal dengan waktu berangkat perjalan pertama di titik awal pada pukul 06.15 WIB dan waktu tiba perjalnan terakhir di titik akhir pada pukul 07.22 WIB.

\section{E. KESIMPULAN}

Kesimpulan yang diperoleh dari hasil penelitian Pemberdayaan Angkutan Umum Sebagai Angkutan Sekolah Di Kecamatan Pare, Kabupaten Kediri adalah jumlah permintaan untuk angkutan sekolah adalah 457 siswa untuk permintaan aktual dan 7761 siswa untuk permintaan potensial. Pergerakan yang ditimbulkan oleh siswa yang paling tinggi berasal dari zona 2, dimana tata guna lahan pada zona tersebut merupakan kawasan permukiman. Kemudian rute rencana untuk pengoperasian angkutan sekolah di Kecamatan Pare dibagi menjadi 2 rute dengan pelayanan rute yang berbeda yaitu: Trayek 1 dengan panjang rute 5,3 km. Trayek ini melayani: JL. Letjen Sutoyo - Jl.Panglima Polim - Jl. Kelapa - Jl. Pb. Sudirman - Jl. Merbabu - Jl. Mayjen Mas Isman Trayek 2 dengan panjang rute 7,1 km Trayek ini melayani : Jl.Raden Ajeng Kartini - Jl. Pahlawan Kusuma Bangsa - Jl. Stadion Canda Bhirawa - Jl. Dr. Sutomo -Jl. Soekarno Hatta. Lalu jumlah armada yang dibutuhkan untuk permintaan aktual pada Rute 1 jumlah kebutuhan armada 1 kendaraan dan Rute 2 jumlah kebutuhan armada 1 kendaraan. Pada permintaan potensial Rute 1 jumlah kebutuhan armada 4 kendaraan dan Rute 2 jumlah kebutuhan armada 4 kendaraan. Berikutnya jadwal rencana untuk pengoperasian angkutan sekolah di Kecamatan Pare dibagi menjadi dua shift yaitu shift pagi pukul 06.15 - 07.15 WIB dan shift siang pada pukul 13.00 - 15.00 WIB dengan pembagian pada permintaan Aktual untuk Rute 1 jumlah perjalanan 1 rit dan Rute 2 jumlah perjalanan 1 rit. Pada Permintaan Potensial untuk Rute 1 jumlah perjalanan 4 rit dan Rute 2 jumlah perjalanan 4 rit. Kemudian tarif yang dikenakan dalam perencanaan operasi angkutan sekolah sebesar $R p 2.840$ /pnp-trip. MPU 1 dan Rp3.282,00/pnp-trip untuk MPU 2 yang dibebankan kepada penumpang untuk tiap perjalanan. Pembayaran dilakukan secara tunai, sehingga tarif yang diusulkan untuk angkutan sekolah sebesar Rp3.000,00/pnp-trip untuk trayek MPU 1 dan Rp3.500,00/pnp-trip untuk trayek MPU 2. Terakhir untuk meningkatkan pelayanan dan kenyamanan pada angkutan sekolah, angkutan sekolah harus mulai beroperasi maksimal dari jam 06.15 untuk shift pagi dan 13.00 untuk shift siang. Selain itu fasilitas di dalam armada angkutan sekolah terpenuhi.

\section{REFERENSI}

1. Abdul Khader Nayati, Mohammed. 2008. School Bus Routing And Scheduling Using Gis. University of Gavle. Swedia

2. Anggaapratam. 2015. Kecamatan Pare Kab Kediri. [diunduh 2020 Mei 28]; tersedia 
pada: ttps://singoutnow.wordpress.com/2015/06/17/kecamatan-pare- kab-kediri/

3. Azmi, Ulul. 2018. Studi Perencanaan Angkutan Pelajar Kota Mataram. Jurusan Teknik Sipil Universitas Mataram. Nusa Tenggara Barat

4. Badan Pusat Statistik Kabupaten Kediri. 2019. Kecamatan Pare Dalam Angka 2019

5. Balai Penyuluh Pertanian Kecamatan Pare. Profil BPP Pare. 2013. Tersedia di

6. Belcher, J., Britt, D., Granade, S., et all. 2005. Bus routing algorithms: Application to a rural school district, ACCLAIM Working Papers 27.

7. Dewa Ayu Dwi Wira Utami, Ketut Wiyana, Putu Eka Purnamaningsih. 2017. Implementasi Program Angkutan Siswa Trans Serasi Dalam Meningkatkan Pelayanan Angkutan Siswa Gratis di Kabupaten Tabanan. Fakultas Ilmu Sosial dan Ilmu Politik Universitas Udayana. Bali

8. Google Inc. 2020. Google Maps: Peta Kecamatan Pare Kabupatten Kediri [diunduh 2020 Februari 15]; tersedia pada: http:///maps.google.com/

9. http://bpp-parekediri.blogspot.com/2013/07/profil-bpp-pare.html

10. Kamus Besar Bahasa Indonesia. [Online]. Tersedia di https://kbbi.kata.web.id/bussekolah. Diakses 18 Januari 2020.

11. Konečný, Vladimír. 2017. Research on Demand for Bus Transport and Transport Habits of High School Students in Žilina Region.

12. Kusmintardjo, 1993. Pengelolaan Layanan Khusus Sekolah. Malang: OPF IKIP Malang

13. Novitasari, Ekyanti. 2018. Perencanaan Angkutan Sekolah Berbasis Angkutan Umum Di Kota Ternate. Skripsi STTD. Bekasi

14. Palupiningtyas, Selenia Ediyani. 2016. Analisis Kebijakan Penyelenggaraan Angkutan Sekolah di Kota Bandung. Badan Penelitian dan Pengembangan Perhubungan. Jakarta

15. Peraturan Menteri Perhubungan Republik Indonesia Nomor 15 Tahun 2019 tentang Penyelenggaraan Angkutan Orang dengan Kendaraan Bermotor Umum dalam Trayek, 2019.

16. Peraturan Menteri Perhubungan Republik Indonesia Nomor 29 Tahun 2015 Tentang Perubahan Atas Peraturan Menteri Perhubungan Nomor PM 98 Tahun 2013 Tentang Standar Pelayanan Minimal Angkutan Orang dengan Kendaraan Bermotor Umum dalam Trayek, 2015.

17. Peraturan Pemerintah Republik Indonesia Nomor 74 Tahun 2014 Tentang Angkutan Jalan, 2014.

18. Pratama, Edwin Dian. 2017. Analisis Kebutuhan Alat Transportasi Sekolah Bagi Siswa Sekolah Lanjutan Tingkat Pertama (Sltp) Se Kecamatan Kedungkandang Kota Malang. Universitas Muhammadiyah Kota Malang. Malang

19. Pusat Data dan Teknologi Informasi Kementrian Pendidikan dan Kebudayaan. 2020. Daftar Sekolah Kecamatan Pare. Jakarta: Kementrian Pendidikan dan Kebudayaan.

20. Sahri, Agus. 2007. Analisis Kesesuaian Time Table Dengan Permintaan Jasa Angkutan Penumpang Umum (Kasus Trayek AKDP Tegal - Purwokerto PP). Program Pascasarjana Universitas Diponegoro. Semarang

21. Sambodja, Ratih Sekartadji. 2015. Studi Demand And Supply Bus Sekolah Untuk Siswa Sekolah Menengah Pertama Dan Atas Di Area Jalan Wijaya Kusuma Surabaya. Program Studi Magister Teknik Sipil FTSP ITS. Surabaya 
22. Surat Keputusan Direktorat Jenderal Perhubungan Darat Nomor 967 Tahun 2007 Tentang Pedoman Teknis Penyelenggaraan Angkutan Sekolah, 2007.

23. Surat Keputusan Direktorat Jendral Perhubungan Darat Nomor 687 Tahun 2002 Tentang Pedoman Teknis Penyelenggraan Angkutan Penumpang Umum di wilayah Perkotaan Dalam Trayek Tetap dan Teratur, 2002.

24. Tim PKL Kabupaten Kediri. 2019. Laporan Umum Transportasi Darat Kabupaten Kediri. STTD. Bekasi.

25. Undang - undang Nomor 22 Tahun 2009 Tentang Lalu Lintas dan Angkutan Jalan, 2009. 